\title{
A Neuro-Fuzzy Approach for Vehicle Fuel Consumption Prediction
}

\author{
Indah Soesanti $^{* 1}$, Ramadoni Syahputra ${ }^{2}$ \\ ${ }^{1}$ Department of Electrical Engineering and Information Technology, Faculty of Engineering, \\ Universitas Gadjah Mada \\ J1. Grafika 2, Kampus UGM, Yogyakarta, Indonesia \\ ${ }^{2}$ Department of Electrical Engineering, Universitas Muhammadiyah Yogyakarta \\ Jl. Lingkar Selatan, Tamantirto, Kasihan, Yogyakarta, Indonesia \\ *Corresponding author, e-mail: indahsoesanti@ugm.ac.id
}

\begin{abstract}
This paper presents a neuro-fuzzy approach for predicting vehicle fuel consumption. The prediction of fuel consumption of a vehicle has become a strategic issue. This is because it is not only related to the problem of the availability of fuel which is getting thinner but also the problem of the environmental impact caused. In this study, the acquisition of the car parameter data was inputted, namely the number of cylinders, displacement, horsepower, weight, acceleration, and model year. The output variable that will be predicted is fuel consumption in miles per gallon (MPG). 'Weight' and 'Year' are chosen as the two best input variables. Training results and predictions are expressed in the three-dimensional input-output surface graph of the best two-input ANFIS model for MPG prediction. The graph shows a nonlinear and monotonic surface, where MPG is predicted to increase with an increase in 'Weight' and a decrease in 'Year'. The results of the RMSE training were 2.767 and the RMSE examination was 2.996. Based on the results of the study showed that the greater the weight of motor vehicles, the greater the amount of fuel needed to travel the same distance.
\end{abstract}

Keywords: Neuro-Fuzzy, Fuel Consumption, MPG, RMSE

\section{Introduction}

In the last two decades, the problem of fuel reserves is very important. This problem requires us to think of anticipatory steps that must be taken. Some anticipatory steps that have been taken are producing fuel-efficient vehicles and using alternative fuels such as biodiesel, bioethanol, hydrogen gas, and others. One of the steps related to fuel savings is to properly manage motor vehicle fuel use. Fuel management is required, especially for each vehicle owner. To properly manage fuel usage, the information needed regarding motor vehicle fuel consumption and vehicle characteristics is considered. This information is useful to be used as a foothold in predicting vehicle fuel consumption [1].

Prediction of vehicle fuel consumption has now become an important issue in the world. This is because it is not only related to the issue of fuel availability but also the problem of environmental impacts caused. Several methods for predicting motor vehicle fuel consumption have been developed including methods based on data speed and vehicle acceleration [2], methods based on maps [3], and adaptive eco-cooperative cruise control at intersections that are marked considering the effects of queues [4]. These methods can be categorized as conventional methods. Since the introduction of the concept of fuzzy logic, this concept has become a new discourse in applications in various fields [5]. The next development is the emergence of artificial neural network methods, which is one of the smart methods.

The application of fuzzy logic will lead to a more adaptive system [6]. For the purposes of prediction and estimation systems, the use of intelligent systems has become an interesting 
problem. Therefore, this study will try to apply the concept of artificial neural networks and fuzzy logic, which is often also known as the ANFIS (Adaptive Neuro-Fuzzy Inference System) method to predict fuel consumption in motor vehicles. The purpose of this research is to study deeper methods through ANFIS adaptive networks and fuzzy logic inference systems and to make accurate device prediction software for motor vehicle fuel consumption using the ANFIS method, which was developed in Matlab software. The main contribution of this research is to the world of education and research or other communities such as industries, banks, and companies that have great interest, directly or indirectly. More concretely, these contributions are detailed as follows: 1) Using the model to be made in this study, users can learn the concepts and ways of ANFIS work on intelligent systems, especially in prediction problems, 2) With an accurate prediction method, the use of fuel for vehicles motorization can be more efficient, and 3 ) From the results of this study it is expected to be useful in fostering new inspiration for the application and development of ANFIS.

The neuro-fuzzy method is a combination of the neural network method and the fuzzy logic method. The neuro-fuzzy method has been widely used in various applications in various fields, including control, estimation, and prediction [7]. The current control system has applied the principles of fuzzy logic called the fuzzy logic controller (FLC). The way it works is similar to the control operator which does not pay attention to the internal structure of the installation. This operator only observes errors as the difference between set-point the output and changes the control panel of system settings to minimize errors.

\section{Literature Study}

\section{II.1 Model of Vehicle Fuel Consumption}

The technological advances that accompanied rapid economic development make the energy becoming key issues for the world community. Car as a mode of transportation today and the future also continues to progress both in terms of quantity and quality. The size of the current car quality is not only located the engine capability and ride comfort, but also on its fuel consumption. The cars produced today are required to use fuel economically, or even have developed the car with fuel is also non-fuel such as electric cars, cars with hydrogen fuel, and others. These steps are carried out because of the depletion of the availability of fuel.

Regardless of the energy problem, it is undeniable that the current vehicle operating in this world is still the majority of oil-fueled. The use of automatic fuel oil could not be avoided the problem of $\mathrm{CO}_{2}$ emissions into the atmosphere, which is a major component in the combustion products. $\mathrm{CO}_{2}$ is a gas that is not toxic, but its presence is highly contested because it increases the influence of greenhouse gases that lead to the depletion of the ozone layer. The burning of fossil fuels also causes a great influence in threatening the availability of oxygen in the air, because it will be replaced by $\mathrm{CO}_{2}$. Therefore it is the duty of the Engineer to think of anticipatory steps in addressing this issue. Related to this issue, there is a method of prediction of fuel consumption is based on a multidimensional engine characteristic.

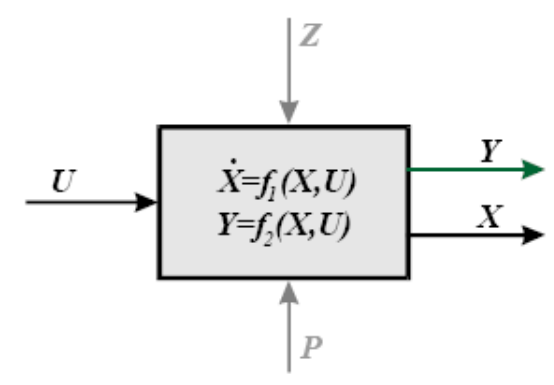

Fig. 1. Schematic of a causal model in the form of state equation

The multidimensional engine characteristics defined using dynamic relationships commonly used in the graphic theory Bond and Equal Circumstances [3], which is in the form of the state equation expressed by:

$$
\begin{aligned}
& X=f 1(X, U) \\
& Y=f 2(X, U)
\end{aligned}
$$

Machine parameters that are important to note in this method is the angular velocity, torque, fluid temperature, oil temperature, $\mathrm{CO}_{2}$ emissions, emissions of $\mathrm{HC}$ and $\mathrm{NO}_{2}$ emissions. Related to the impact caused by the oil-fueled vehicles in the form of exhaust emissions endanger human health and the environment, the use of fuel for vehicles need to be managed properly. One step fuel management is to know clearly the needs of the fuel consumption. For this reason in this study predicted vehicle fuel consumption. 


\section{II.2. ANFIS Technique}

ANFIS technique has been became a popular method in many application. A brief description of the principles of Adaptive neuro-fuzzy inference system (ANFIS) which are referred to [5] is described in this section. The basic fundamental structure of the type of fuzzy inference system could be seen as a model that maps input characteristics to input membership functions. Then it maps input membership function to rules and rules to a set of output characteristics. Finally it maps output characteristics to output membership functions, and the output membership function to a single valued output or a decision associated with the output.

The neuro-adaptive learning method works similarly to that of neural networks. Neuro-adaptive learning techniques provide a method for the fuzzy modeling procedure to learn information about a data set. It computes the membership function parameters that best allow the associated fuzzy inference system to track the given input/output data. A network-type structure similar to that of a neural network can be used to interpret the input/output map so it maps inputs through input membership functions and associated parameters, and then through output membership functions and associated parameters to outputs,. The parameters associated with the membership functions changes through the learning process. The computation of these parameters (or their adjustment) is facilitated by a gradient vector. This gradient vector provides a measure of how well the fuzzy inference system is modeling the input/output data for a given set of parameters. When the gradient vector is obtained, any of several optimization routines can be applied in order to adjust the parameters to reduce some error measure (performance index). This error measure is usually defined by the sum of the squared difference between actual and desired outputs. ANFIS uses a combination of least squares estimation and back propagation for membership function parameter estimation.

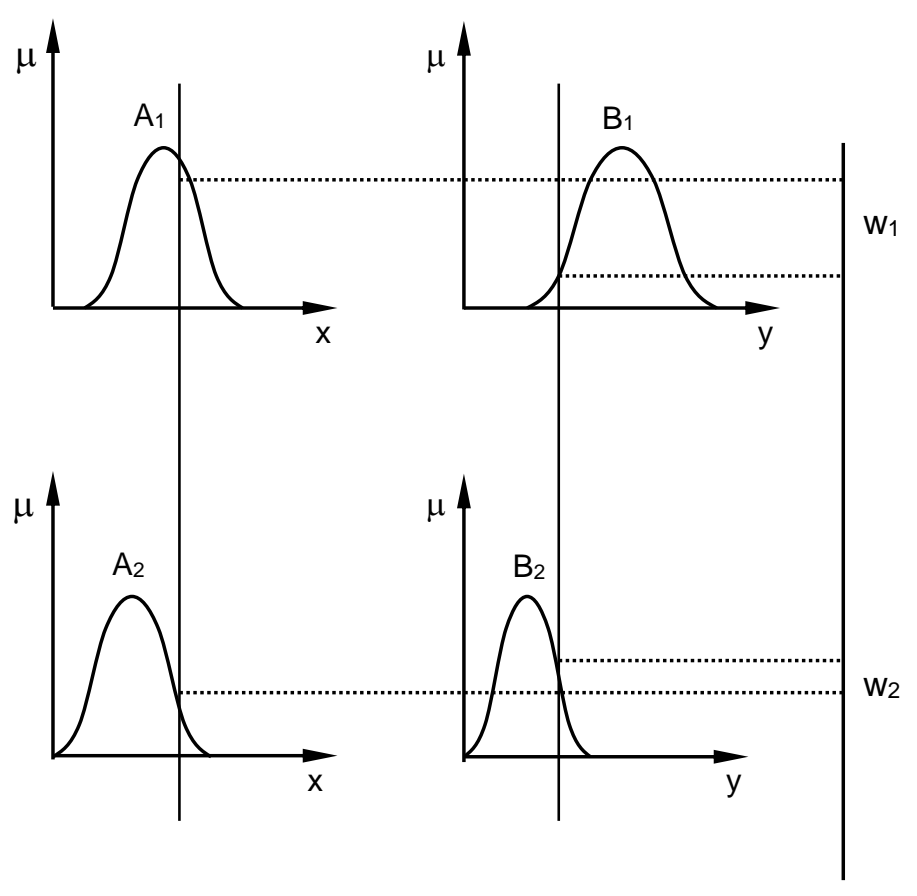

$$
\begin{gathered}
f_{1}=p_{1} x+q_{1} y+r_{1} \\
f_{2}=p_{2} x+q_{2} y+r_{2} \\
\quad \downarrow \\
f=\frac{w_{1} f_{1}+w_{2} f_{2}}{w_{1}+w_{2}}
\end{gathered}
$$

Fig. 2. Sugeno's fuzzy logic model 
$\begin{array}{llll}\text { Layer } 1 & \text { Layer } 2 & \text { Layer } 3 & \text { Layer } 4\end{array}$

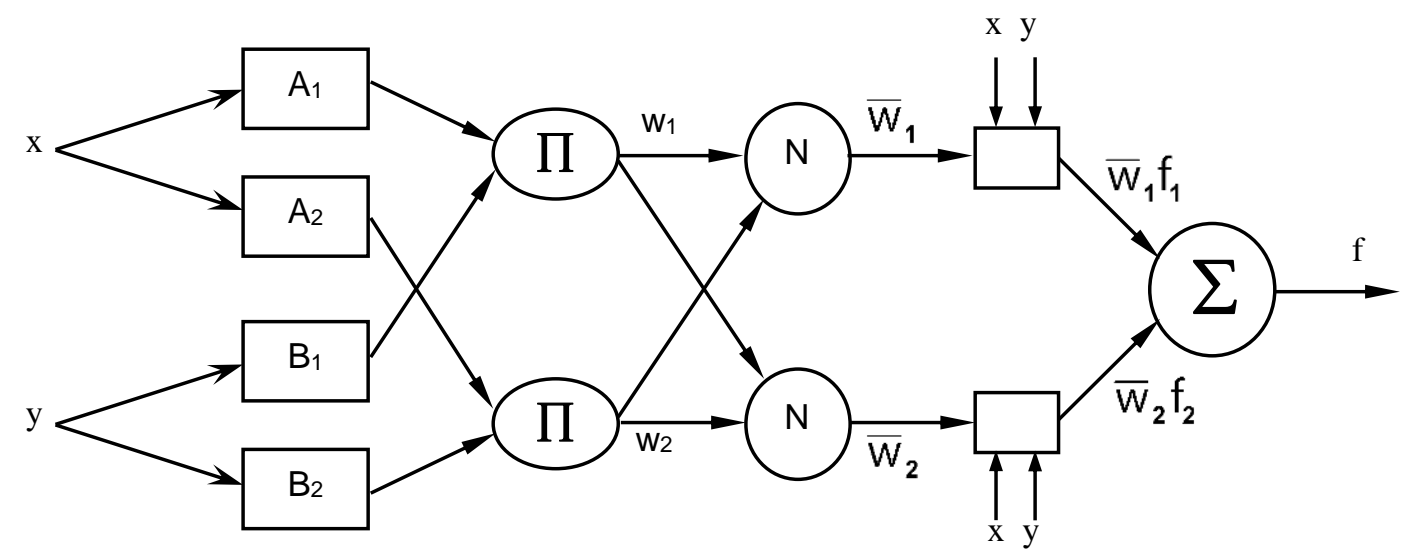

Fig. 3. The architecture of the 2-input and 1-output ANFIS

The suggested ANFIS has several properties:

1. The output of ANFIS is zero-th order Sugenotype system.

2. ANFIS has a single output, obtained using defuzzification of weighted average.

3. ANFIS has no rule for sharing. Different rules do not share for output membership function that has the same value.

4. ANFIS has unity weight for each rule.

Figure 1 shows Sugeno's fuzzy logic model. Figure 2 shows the ANFIS architecture, comprising by input layer, fuzzification layer, inference later, and defuzzification layer. The network can be visualized as consisting of inputs, with $\mathrm{N}$ neurons in the input layer and $\mathrm{F}$ input membership functions for each input, using $\mathrm{F}^{*} \mathrm{~N}$ neurons in the layer of fuzzification. In this case, there are FN rules with FN neurons in the inference while there are defuzzification layers and one neuron in the output layer. It is assumed that the FIS under consideration has two inputs $\mathrm{x}$ and $\mathrm{y}$ and one output $\mathrm{z}$, as can be seen in Figure 2. For a zero-order in Sugeno fuzzy model as used in this research, a common rule set with two fuzzy if-then rules is the following:

Rule 1: If $\mathrm{x}$ is $\mathrm{A} 1$ and $\mathrm{y}$ is $\mathrm{B} 1$, Then $\mathrm{f} 1=\mathrm{r} 1$

Rule 2: If $x$ is $A 2$ and $y$ is $B 2$, Then $f 2=r 2$

The output of the node $\mathrm{i}$-th in layer $\mathrm{n}$ is denoted as $\mathrm{O}_{\mathrm{n}, \mathrm{i}}$ :

Layer 1. Every node $\mathrm{i}$ in this layer is a square node with a node function:

$$
\begin{aligned}
& \mathrm{O}_{\mathrm{i}}^{1}=\mu \mathrm{Ai}(\mathrm{x}), \text { for } \mathrm{i}=1,2, \\
& \quad \text { or, } \\
& \mathrm{O}_{\mathrm{i}}^{1}=\mu \mathrm{Bi}-2(\mathrm{y}), \text { for } \mathrm{i}=3,4
\end{aligned}
$$

where $\mathrm{x}$ is the input to node- $\mathrm{i}$, and $\mathrm{Ai}$ is the linguistic label (small , large, etc.) associated with this node function. In other words, $\mathrm{O}_{i}^{1}$ is the membership function of $\mathrm{Ai}$ and it specifies the degree to which the given $x$ satisfies the quantifier Ai. Usually $\mu \mathrm{Ai}(\mathrm{x})$ is chosen to be bell-shaped with maximum equal to 1 and minimum equal to 0 , such as the generalized bell function:

$$
\mu_{\mathrm{A}}(\mathrm{x})=\frac{1}{1+\left[\frac{\mathrm{x}-\mathrm{c}_{\mathrm{i}}}{\mathrm{a}_{\mathrm{i}}}\right]^{2 b_{\mathrm{i}}}}
$$

The parameters are referred to as premise parameters.

Layer 2. Every node in this layer is a circle node labelled $\Pi$ which multiplies the incoming signals and sends the product out. For instance,

$$
\mathrm{O}_{\mathrm{i}}^{2}=w \mathrm{i}=\mu \mathrm{Ai}(\mathrm{x}) \mathrm{x} \mu \mathrm{B}(\mathrm{y}), \mathrm{i}=1,2 .
$$

Each node output represents the firing strength of a rule. (In fact, other T-norm operators that performs generalized AND can be used as the node function in this layer.)

Layer 3. Every node in this layer is a circle node labeled N. The i-th node calculates the ratio of the ith rule's firing strength to the sum of all rules firing 
strengths:

$$
\mathrm{O}_{\mathrm{i}}^{3}=\overline{\mathrm{w}}=\frac{\mathrm{w}_{\mathrm{i}}}{\mathrm{w}_{1}+\mathrm{w}_{2}}, \quad \mathrm{i}=1,2 .
$$

For convenience, outputs of this layer will be called normalized firing strengths.

Layer 4. Every node $\mathrm{i}$ in this layer is a square node with a node function:

$$
\mathrm{O}_{\mathrm{i}}^{4}=\overline{\mathrm{w}}_{\mathrm{i}} \mathrm{f}_{\mathrm{i}}=\overline{\mathrm{w}}_{\mathrm{i}}\left(\mathrm{p}_{\mathrm{i}} \mathrm{x}+\mathrm{q}_{\mathrm{i}} \mathrm{y}+\mathrm{r}_{\mathrm{i}}\right)
$$

where $\overline{\mathrm{W}}_{\mathrm{i}}$ is the output of layer 3 , and \{pi, qi, ri $\}$ is the parameter set. Parameters in this layer will be referred to as consequent parameters.

Layer 5. The single node in this layer is a circle node labeled $\Sigma$ that computes the overall output as the summation of all incoming signals, i.e.,

$$
\mathrm{O}_{\mathrm{i}}^{5}=\sum \overline{\mathrm{w}}_{\mathrm{i}} \mathrm{f}_{\mathrm{i}}
$$

\section{Methodology}

Intelligent systems design model for the prediction of the fuel consumption of motor vehicles generally consist of three stages, namely the collection of training data (Figure 4), ANFIS training process (Figure 5), and the use of predictors ANFIS (Figure 6). In the process of data collection training, data collected in the form of fuel oil consumption for a wide range of vehicle brands with regard six input attributes that the number of cylinders, displacement, power, weight, acceleration, and the year of manufacture. Variable output fuel consumption of vehicles is concerned, the architectural design of ANFIS in this study, based on Figure 2 that can use Sugeno ANFIS models.

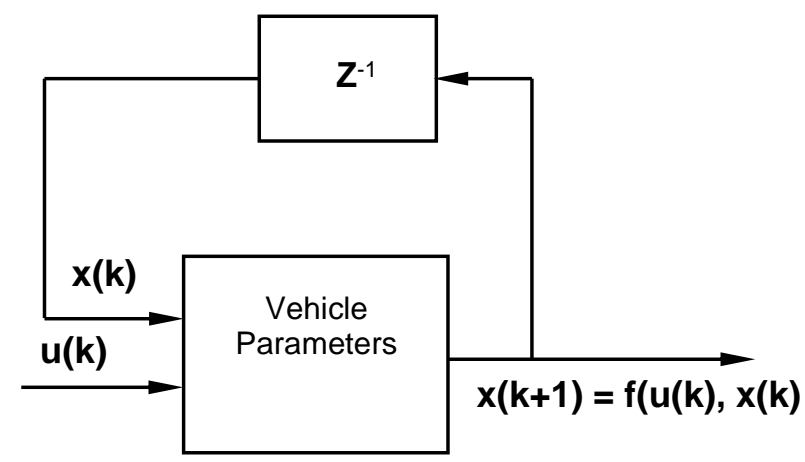

Figure 4. Block diagram of the input and output of data collection

In Figure 4, the value of $x(x+1)$ is the output of a function that has the input $\mathrm{u}(\mathrm{k})$ and $\mathrm{x}(\mathrm{k})$. So in this case a motor vehicle is a function that depends on the previous output. The next training is on ANFIS to the data inputs and outputs. The training structure is shown in Figure 5.

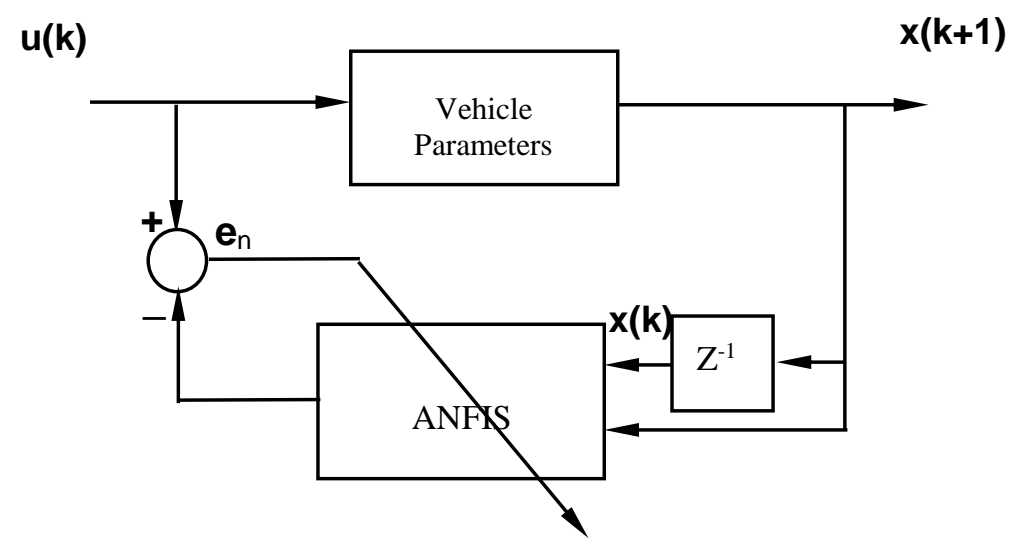

Fig. 5. ANFIS training process

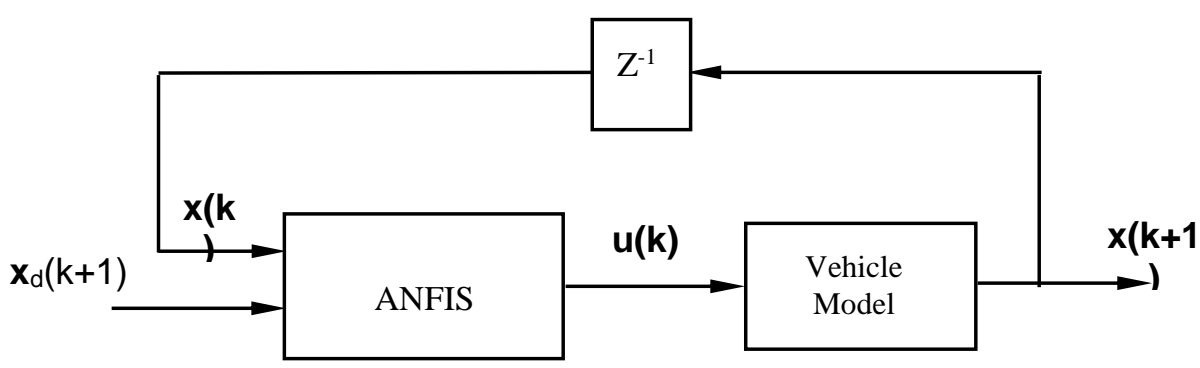

Fig. 6. Aplication process of ANFIS predictor 
Training data used in the plant according Figure 5 has the following format:

$$
[\mathrm{x}(\mathrm{k}), \mathrm{x}(\mathrm{k}+1), \mathrm{u}(\mathrm{k})]
$$

The first two columns of data is the data being input ANFIS last column is the data output of the ANFIS. Training data is obtained by inserting a random value with a magnitude of between -1 and 1 to obtain $x(k)$ and $x(k+1)$. Training is done by entering the value $\mathrm{x}(\mathrm{k})$ and $\mathrm{x}(\mathrm{k}+1)$ which have been obtained ANFIS then ANFIS output compared with the value $\mathrm{u}(\mathrm{k})$. Once the data is obtained and ANFIS training has been trained, then ANFIS training results are used to predict the consumption of fuel for motor vehicles, as shown in Figure 6.

\section{Results and Discussion}

\section{IV.1 ANFIS Training}

In this study addressed the use of methods ANFIS (Adaptive Neuro Fuzzy Inference Systems) to predict the fuel consumption of motor vehicles, especially cars. ANFIS method in this study utilizing the toolbox contained in the software MATLAB, the Fuzzy Logic Toolbox. In this case the function used is ANFIS function. Prediction fuel is needed in order to plan for the car especially for the purpose of the trip with a very far distance. Prediction fuel often referred to as a prediction MPG (miles per gallon), a prediction measure how far that can be reached by a car for every one gallon of fuel.

Prediction MPG (miles per gallon) is a problem that is nonlinear regression, in which some of the completeness of the information profiles of a car is needed to predict the fuel consumption in MPG. Therefore, a relevant data is pertaining to the use of the fuel of a car, and also for the cars of other products. In this study, used for ANFIS training data obtained from data provided by the UCI (Univ. of California at Irvine) Machine Learning Repository. The address contained in the data collected from the cars with different models and brands, as shown in Table 1. The table shows some tuple of the data set MPG (miles per gallon). Six attribute input consists of a number of cylinders, displacement, power (HP), weight $(\mathrm{kg})$, acceleration, and model year. Furthermore, the output variables to be predicted are the fuel consumption in MPG (miles per gallon). Brands and models of cars are shown in the first column of Table 1 is not used in this prediction, and is shown only for the supporting information. The set of data obtained from the original data file 'auto-gas.dat'. Then the data set is partitioned into a training set (tuple indexed odd) and the set of checks (tuple indexed even), and use the function 'exhsrch' to find the input attributes that have better predictive power for ANFIS modelling.

To select the best input attributes, 'Exarch' construct six ANFIS, each with a single input attribute. In this case the results after execution exhsrch are (1, trn_data, chk_data, input_name). It can be seen that 'Weight' is the most influential input attribute, then the attributes most influential input two numbers is 'disp', and so on. Error training and checking than its size, which implies that there is no overfitting and can be selected more input variables. Based on intuition, it can be simplified with selecting 'Weight' and 'disp' directly. But not required two-ANFIS models with minimal training error. To prove this, it can be done by activating the command exhsrch (2 trn_data, chk_data, input_name) to select the two best entries of all combinations.

TABLE I

TEChNical Data of CARS OF Different BRANDS

\begin{tabular}{cccccccc}
\hline \hline \multirow{2}{*}{$\begin{array}{c}\text { Automobile } \\
\text { Name }\end{array}$} & \multicolumn{9}{c}{\begin{tabular}{c} 
Input Data \\
\cline { 2 - 8 } \\
\cline { 2 - 8 } \\
Cylinders
\end{tabular}} & $\begin{array}{c}\text { Displace- } \\
\text { ment }\end{array}$ & $\begin{array}{c}\text { Power } \\
\text { (HP) }\end{array}$ & Weight & Acceleration & Years & MPG \\
\hline $\begin{array}{c}\text { Chevrolet } \\
\text { Chevelle Malibu }\end{array}$ & 8 & 307 & 130 & 3504 & 12 & 1970 & 18 \\
Plymouth Duster & 6 & 198 & 95 & 2803 & 15.5 & 1970 & 22 \\
$\quad$ Fiat 128 & 4 & 90 & 75 & 2108 & 15.5 & 1974 & 24 \\
Oldsmobile & 8 & 260 & 110 & 4050 & 19 & 1977 & 17 \\
Cutlass Supreme & 4 & 89 & 62 & 2050 & 17.3 & 1981 & 37.7 \\
$\quad$ Toyota & 4 & 107 & 75 & 2205 & 14.5 & 1982 & 36 \\
Honda Accord & 4 & 120 & 79 & 2625 & 18.6 & 1982 & 28 \\
Ford Ranger & 4 & & & & &
\end{tabular}




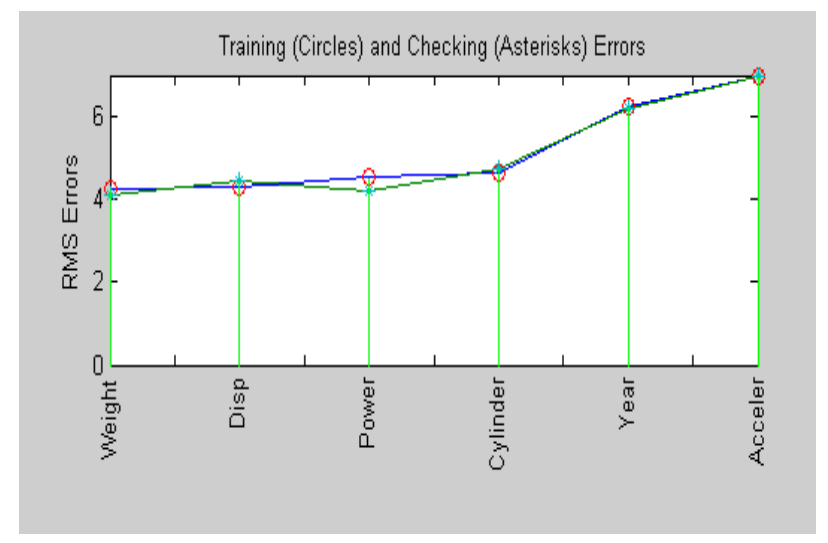

Fig. 7. Training error and checking of 6 ANFIS model

To demonstrate the results of the two inputs is selected. It can be done by selecting the 'Weight' and 'Year' as the best two input variables. Error training direct inspection can be distinguished, which indicates the beginning of overfitting. As a comparison, it can be used exhsrch to choose three inputs, namely:

$$
\begin{aligned}
& \text { input_index }=\operatorname{exhsrch}(2 \text {, trn_data, chk_data, } \\
& \text { input_name); } \\
& \text { new_trn_data }=\quad \text { trn_data(:, } \quad \text { input_index, } \\
& \text { size(trn_data,2)]); } \\
& \text { new_chk_data = chk_data(:, [input_index, } \\
& \text { size(chk_data,2)]); } \\
& \text { win2 = gcf; }
\end{aligned}
$$

Furthermore, the training of 15 ANFIS models, each with two inputs selected from six candidates, as can be seen in Figure 8.

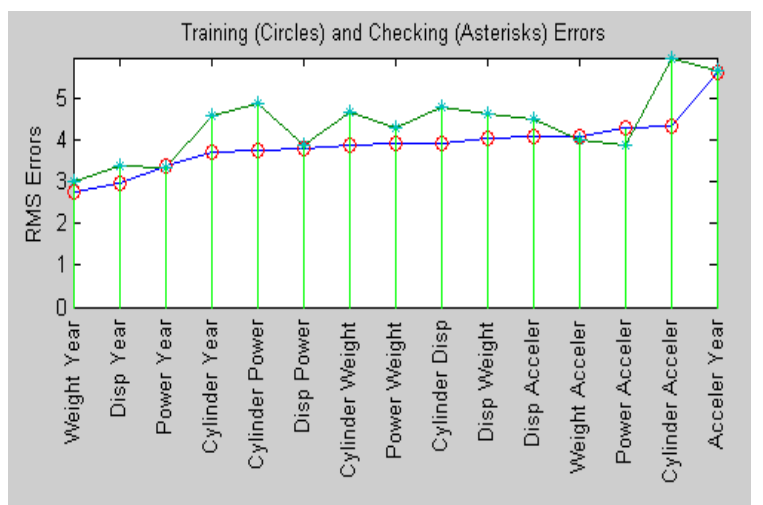

Fig. 8. Training error and checking of 15 ANFIS model

Figure 8 shows the results of the election of three entries, with 'Weight', 'Year' and 'Acceler' were chosen as the best three input variables. It can be seen that the minimum training error (and checks) is not significantly reduced from 2 -input models best, indicating that the addition of new attributes 'Acceler' not able to improve significantly predicted outcome. For better generalization, then it was preferably a model with a simple structure. Therefore in this case will be applied two ANFIS inputs for further exploration, namely:

$$
\begin{aligned}
& \text { exhsrch(3, trn_data, chk_data, input_name); } \\
& \text { in3 = gcf; }
\end{aligned}
$$

Furthermore, trained 20 ANFIS models, each with 3 inputs selected from six candidates, as can be seen in Figure 9.

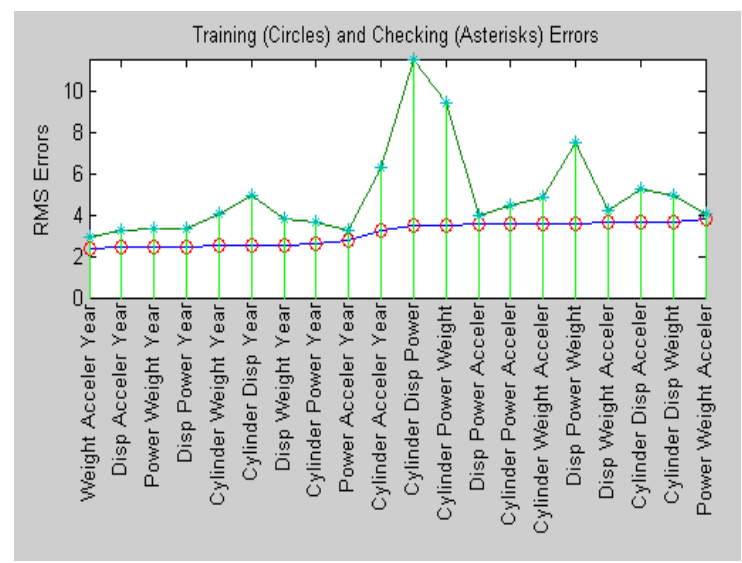

Fig. 9. Training error and checking of 20 ANFIS model

In Figure 9 is shown the surface of the inputoutput model of the two-input ANFIS best for prediction MPG. In the picture it is shown that the model is nonlinear and monotonous surface, with the predictable increase MPG in the event of an increase in 'Weight' dam drop in 'Year'. Value RMSE (root mean squared error) is training 2,767 and RMSE check is 2,996. As a comparison, performed by simple linear regression using all the candidates input produces training RMSE is 3.4527 , and the checking RMSE is 3.4444 .

\section{IV.2 Vehicle Fuel Prediction}

In Figure 10 has shown the results of prediction of fuel (LPG) vehicles based on weight in kilograms $(\mathrm{kg})$. Based on the graph, it is shown that the greater the weight of the vehicle, then the value of MPG (miles per gallon) is getting smaller. This means that the greater the weight of the vehicle, the greater the amount of fuel needed to travel the same distance. Year car output also affects fuel efficiency, ie the higher the output, the higher fuel efficiency. As an example of the prediction of the graph in Figure 10, for car output in 1970 with a weight of $2000 \mathrm{~kg}$, the fuel consumption is 25 miles per gallon, while the car to output the same year 
with a weight of $4000 \mathrm{~kg}$, the fuel consumption of 10 mile per gallon. In comparison, for the car output in 1982 with a weight of $2000 \mathrm{~kg}$, the fuel consumption is 38 mile per gallon, while the car to output the same year with a weight of $4500 \mathrm{~kg}$, the fuel consumption of 22 mile per gallon.

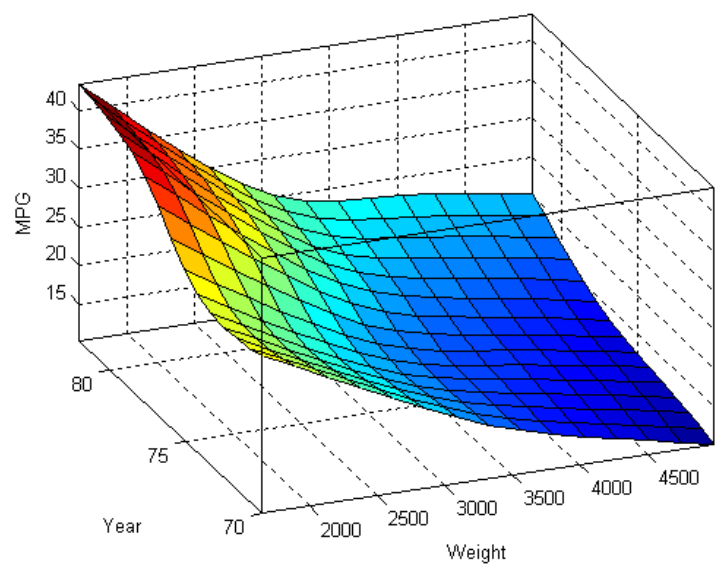

Fig. 10. MPG chart predicted results based on the weight of motor vehicles

Exhsrch function is only ANFIS to train every single epoch in order to find the correct input briefly. Once the input is set, it will take longer for ANFIS training. Plot in Figure 11 shows the error curve for 100 epoch ANFIS training. Green curve shows the error of training, while the red curve shows the error-checking. Minimal error checking occurs during epoch 45, characterized by circle. Notice that the curve of error checking to rise after 50 epochs, indicating that further training will occur overfitting the data and produce a poor generalization.

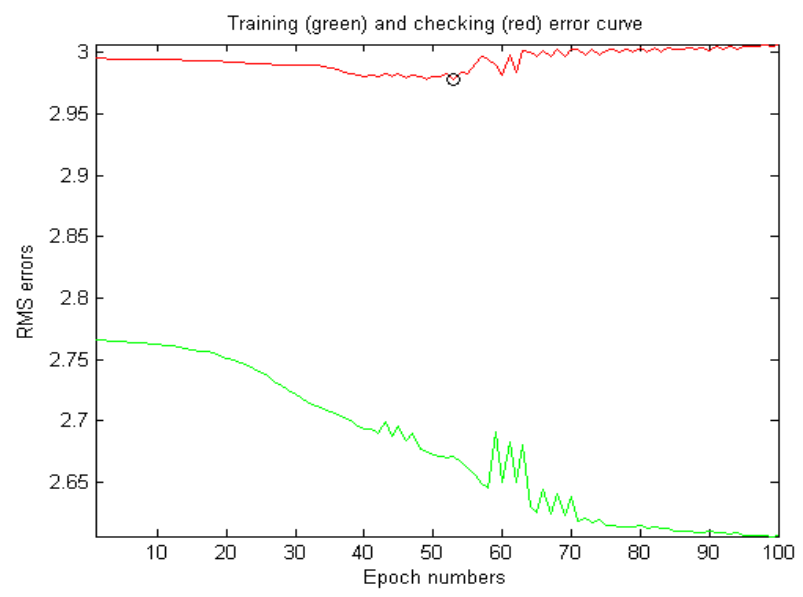

Fig. 11. Error curve for 100 epochs of ANFIS training

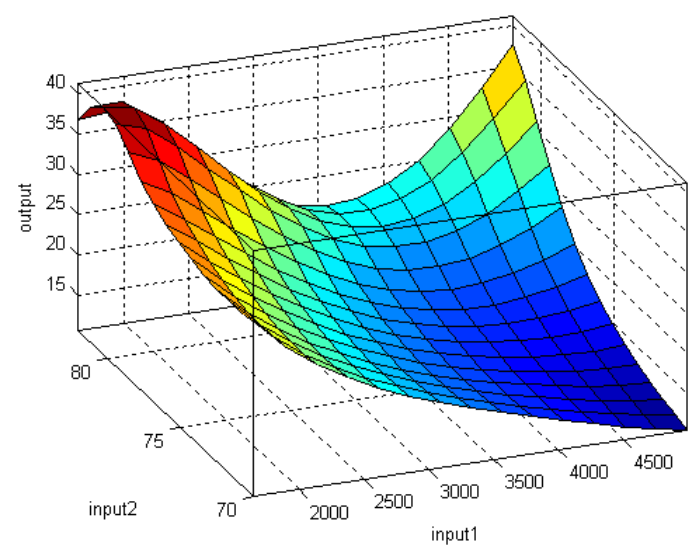

Fig. 12. Graph the results predicted MPG vehicles based on two-input

ANFIS chart for two-inputs at a minimum measurement error is shown in Figure 12. In the image has shown input-output surface. The checking training error and lower than before, but it can be seen some spurious effects at the end of the end surface. On the curve can be stated also that car production for the year higher, the greater the weight of the car will be obtained by the use of fuels that are relatively efficient. This result contradicts the previous results as shown in Figure 10 , which is caused by a shortage amount of data used in training. This lack of data due to the difficulty of getting data about the parameters of the car that will be used in training ANFIS. Figure 13 shows the distribution of the training data and checking ANFIS. Shortcomings in terms of the amount of training data on the top right corner of the spurious cause ANFIS surface as described earlier. Therefore, fuel consumption prediction using ANFIS should be interpreted with due regard to the distribution of the data as shown in Figure 13.

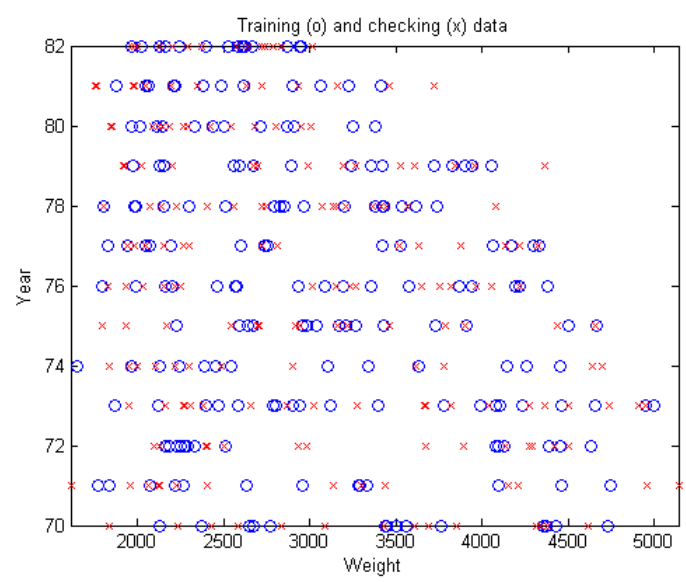

Fig. 13. Distribution of training data and checking of ANFIS 


\section{Conclusion}

Based on the results of the training and checking ANFIS, the chosen model of a two-input ANFIS best for prediction MPG, i.e. "Weight" and "Year", has a minimum value of both training RMSE and RMSE checking. The training RMSE is 2,767 and checking RMSE check is 2,996. The greater the weight of the motor vehicle, the greater the amount of fuel needed to travel the same distance. Year car output also affects fuel efficiency, i.e. the higher the output, the higher fuel efficiency. For example predicted results, for car output in 1970 with a weight of $2000 \mathrm{~kg}$, the fuel consumption is 25 miles per gallon, while the car to output the same year with a weight of $4000 \mathrm{~kg}$, the fuel consumption of 10 miles per gallon. In comparison, for the car output in 1982 with a weight of $2000 \mathrm{~kg}$, the fuel consumption is 38 miles per gallon, while the car to output the same year with a weight of $4500 \mathrm{~kg}$, the fuel consumption of 22 miles per gallon.

\section{References}

[1] K. Ahn, H. Rakha, A. Trani, M. Van-Aerde, (2001), "Estimating Vehicle Fuel Consumption and Emissions Based on Instantaneous Speed and Acceleration Levels", IEEE Pappers, New York.

[2] J. Kropiwnicki, (2002), "The Possibilities of Using of The Engine Multidimensional Characteristic in Fuel Consumption Prediction", Journal of KONES Internal Combustion Engines 2002 No. 1-2.

[3] L.L. Ojeda, A. Chasse, R. Goussault, (2017), "Fuel consumption prediction for heavy-duty vehicles using digital maps," 2017 IEEE 20th International Conference on Intelligent Transportation Systems (ITSC), Yokohama, Japan, 16-19 Oct. 2017.

[4] H. Yang, H. Rakha, M.V. Ala, (2017), "EcoCooperative Adaptive Cruise Control at Signalized Intersections Considering Queue Effects," IEEE Transactions on Intelligent Transportation Systems, Vol. 18, No. 6, June 2017, pp. 1575 - 1585.

[5] J.S.R. Jang, (1993), "ANFIS: Adaptive-Networkbased Fuzzy Inference System", IEEE Trans. Syst., Man, Cybern., 23, 665-685, June.

[6] R. Syahputra, (2012), "Fuzzy Multi-Objective Approach for the Improvement of Distribution Network Efficiency by Considering DG", IJCSIT, Vol. 4, No. 2, pp. 57-68.

[7] J.S. Wang, C.S.G. Lee, (2002), "Self-Adaptive Neuro-Fuzzy Inference Systems for Classification Applications", IEEE Trans. on Fuzzy Systems, 10, 6, Dec, 2002.

\section{Authors' information}

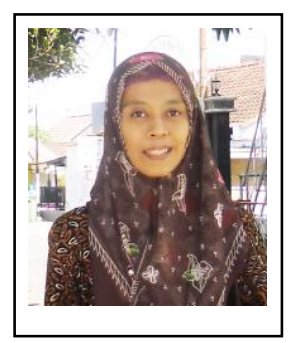

Indah Soesanti was born on June 15, 1974. She received both M.Eng. and Ph.D. degrees from Department of Electrical Engineering, Gadjah Mada University, Yogyakarta, Indonesia in 2001 and 2011, respectively.

Dr. Indah Soesanti is a Lecturer in the Department of Electrical Engineering and Information Technology, Faculty of Engineering, Universitas Gadjah Mada, Indonesia. Her research interests are in signal processing, image processing, control system, ICT-based system, optimization, artificial intelligence in signal processing pattern classification, and artificial intelligence in control system.

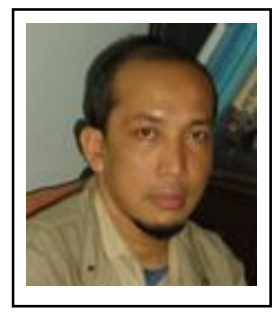

Ramadoni Syahputra received B.Sc. degree from Institut Teknologi Medan in 1998, M.Eng. degree from Department of Electrical Engineering, Universitas Gadjah Mada, Yogyakarta, Indonesia in 2002, and Ph.D. degree at the Department of Electrical Engineering, Faculty of Industrial Technology, Institut Teknologi Sepuluh Nopember, Surabaya, Indonesia in 2015.

Dr. Ramadoni Syahputra is a Lecturer in Department of Electrical Engineering, Faculty of Engineering, Universitas Muhammadiyah Yogyakarta, Indonesia. His research interests are in computational of power system, artificial intelligence in power system, power system control, the application of fuzzy logic in power system, optimization, distributed energy resources, and renewable energy. 